\title{
Carrageenan as an alternative coating for papaya (Carica papaya L. cv. Eksotika).
}

\begin{abstract}
Edible coatings are gaining popularity compared to other types of packaging due to their more environmental friendly nature and ability to carry active ingredients. In this study, a two-factor central composite design (CCD) was used to optimize a carrageenan-based edible coating formulation for coating of 'Eksotika' papayas. The effect of a carrageenan-based [carrageenan $(0.2-0.8 \%, \mathrm{w} / \mathrm{v})$ and glycerol $(0-1 \%, \mathrm{w} / \mathrm{v})$ ] coating on firmness and colour components ( $\mathrm{L}, \mathrm{a}$ and $\mathrm{b}$ values) of papaya was evaluated. From the optimization study, no significant $(\mathrm{p}>0.05)$ lack of fit was found for the reduced model for all response variables (firmness, L, a and b values) tested. Coefficients of determination (R2) ranging from 0.767 to 0.952 were obtained for these responses. From the multiple response optimization analysis, a combination of $0.78 \%(\mathrm{w} / \mathrm{v})$ carrageenan with $0.85 \%(\mathrm{w} / \mathrm{v})$ glycerol for a carrageenan-based coating was predicted to give desirable effects for the response variables tested, with no significant $(\mathrm{p}>0.05)$ differences between the experimental and predicted values.
\end{abstract}

Keyword: Edible coating; Carrageenan; Eksotika papaya; Firmness; Colour; RSM. 